\title{
Efficacy and safety of CD19 CAR T constructed with a new anti-CD19 chimeric antigen receptor in relapsed or refractory acute lymphoblastic leukemia
}

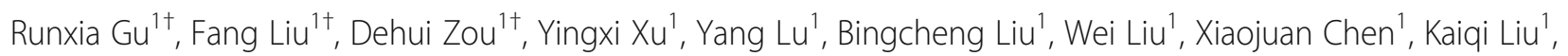
Ye Guo ${ }^{1}$, Xiaoyuan Gong ${ }^{1}$, Rui Lv ${ }^{1}$, Xia Chen ${ }^{1}$, Chunlin Zhou' ${ }^{1}$, Mengjun Zhong ${ }^{1}$, Huijun Wang ${ }^{1}$, Hui Wei ${ }^{1}$, Yingchang Mi', Lugui Qiu', Lulu Lv², Min Wang ${ }^{1}$, Ying Wang ${ }^{1 *}$, Xiaofan Zhu ${ }^{1 *}$ and Jianxiang Wang ${ }^{1 *}$ (D)

\begin{abstract}
Background: Recent evidence suggests that resistance to CD19 chimeric antigen receptor (CAR)-modified T cell therapy may be due to the presence of CD19 isoforms that lose binding to the single-chain variable fragment (scFv) in current use. As such, further investigation of CARs recognize different epitopes of CD19 antigen may be necessary.
\end{abstract}

Methods: We generated a new CD19 CAR T (HI19a-4-1BB-ל CAR T, or CNCT19) that includes an scFv that interacts with an epitope of the human CD19 antigen that can be distinguished from that recognized by the current FMC63 clone. A pilot study was undertaken to assess the safety and feasibility of CNCT19-based therapy in both pediatric and adult patients with relapsed/refractory acute lymphoblastic leukemia (R/R B-ALL).

Results: Data from our study suggested that $90 \%$ of the 20 patients treated with infusions of CNCT19 cells reached complete remission or complete remission with incomplete count recovery (CR/CRi) within 28 days. The CR/CRi rate was $82 \%$ when we took into account the fully enrolled 22 patients in an intention-to-treat analysis. Of note, extramedullary leukemia disease of two relapsed patients disappeared completely after CNCT19 cell infusion. After a median follow-up of 10.09 months (range, 0.49-24.02 months), the median overall survival and relapse-free survival for the 20 patients treated with CNCT19 cells was 12.91 months (95\% confidence interval [Cl], 7.74-18.08 months) and 6.93 months (95\% Cl, 3.13-10.73 months), respectively. Differences with respect to immune profiles associated with a long-term response following CAR T cell therapy were also addressed. Our results revealed that a relatively low percentage of $\mathrm{CD}^{+}$naïve T cells was an independent factor associated with a shorter period of relapse-free survival ( $p=0.012,95 \% \mathrm{Cl}, 0.017-0.601)$.

(Continued on next page)

\footnotetext{
* Correspondence: wangying1@ihcams.ac.cn; xfzhu@ihcams.ac.cn;

wangjx@ihcams.ac.cn

${ }^{\dagger}$ Runxia Gu, Fang Liu and Dehui Zou contributed equally to this work.

'State Key Laboratory of Experimental Hematology, National Clinical Research Center for Blood Diseases, Institute of Hematology \& Blood Diseases Hospital,

Chinese Academy of Medical Sciences \& Peking Union Medical College,

Tianjin 300020, China

Full list of author information is available at the end of the article
}

C C The Author(s). 2020 Open Access This article is licensed under a Creative Commons Attribution 4.0 International License, which permits use, sharing, adaptation, distribution and reproduction in any medium or format, as long as you give appropriate credit to the original author(s) and the source, provide a link to the Creative Commons licence, and indicate if changes were made. The images or other third party material in this article are included in the article's Creative Commons licence, unless indicated otherwise in a credit line to the material. If material is not included in the article's Creative Commons licence and your intended use is not permitted by statutory regulation or exceeds the permitted use, you will need to obtain permission directly from the copyright holder. To view a copy of this licence, visit http://creativecommons.org/licenses/by/4.0/ The Creative Commons Public Domain Dedication waiver (http://creativecommons.org/publicdomain/zero/1.0/) applies to the data made available in this article, unless otherwise stated in a credit line to the data. 
(Continued from previous page)

Conclusions: The results presented in this study indicate that CNCT19 cells have potent anti-leukemic activities in patients with R/R B-ALL. Furthermore, our findings suggest that the percentage of $C D 8^{+}$nairve $T$ cells may be a useful biomarker to predict the long-term prognosis for patients undergoing CAR T cell therapy.

Trial registration: ClinicalTrials.gov: NCT02975687; registered 29 November, 2016. https://clinicaltrials.gov/ct2/ keydates/NCT02975687

Keywords: Chimeric antigen receptor-modified T cell, Single-chain variable fragment, Acute lymphoblastic leukemia, HI19a

\section{Background}

Chimeric antigen receptor-modified $\mathrm{T}$ cells (CAR $\mathrm{T}$ cells) directed against CD19 have shown promise as a novel therapy for hematological malignancies; complete remission (CR) has been achieved in as many as 70-90\% of cases of relapsed/refractory acute lymphoblastic leukemia (R/R B-ALL) [1-5]. Unfortunately, $40-50 \%$ of patients responding to this therapy relapse within 1 year, and nearly half of these relapses included CD19-positive leukemic cells [2-5], while many efforts have been made to improve the design and production of the CAR [6-8]. Recent studies indicate that relapse may be due to mutations in CD19 that destroy the cognate epitope recognized by the anti-CD19 single-chain variable fragment $(\mathrm{scFv})$, such as FMC63 clone, thus rendering the tumor cells invisible to CD19 CAR T cells $[9,10]$. In cases such as these, an exploration of CD19 CAR $\mathrm{T}$ with scFvs capable of binding to different CD19 epitopes may provide alternative choice for patients with mutations in CD19. Results from our previous study revealed that CD19 CAR $T$ cells constructed in our laboratory that were derived from the new HI19 $\alpha$ clone (HI19 $\alpha-4-1 B B-\zeta$ CAR $\mathrm{T}$, or CNCT19) were highly effective when evaluated in preclinical models [11]. Here, we showed that the scFv generated by the HI19 $\alpha$ clone detects a different binding epitopes on the CD19 extracellular domain (ECD) than that detected by FMC63. And we present a single-arm, open-label, non-randomized, prospective pilot study that was conducted to evaluate the safety and efficacy of CNCT19 cells in both children and adult patients with R/R B-ALL.

Furthermore, it is also critical to recognize that despite the impressive initial $C R$ rates associated with current CD19 CAR T therapies for B-ALL, long-term follow-up has revealed that a significant proportion of patients relapse after treatment. As such, more efforts are needed to identify biomarkers that can predict the long-term response to CAR $\mathrm{T}$ cell therapy. Retrospective analyses from clinical trials indicate that inadequate clinical responses to CAR $\mathrm{T}$ cell therapy might also be associated with an insufficient expansion and persistence of functional CAR T cells in vivo [3, 12]. Preclinical human tumor xenograft models have been used to examine the potency of genetically modified $\mathrm{T}$ cells derived from different subsets that are isolated prior to transduction [13-15]. These results revealed that CAR $T$ cells generated from less differentiated $\mathrm{T}$ cell subsets exhibited more proliferative potential and anti-tumor activity than did those derived from differentiated cell subsets [1618]. However, it is not yet clear whether the expansion kinetics of different $\mathrm{T}$ cell subsets are associated with differential responses observed with respect to long-term patient responses to therapy. Likewise, the anti-tumor capabilities of some $\mathrm{T}$ cell subsets, such as $\mathrm{CD}^{+}$central memory $\mathrm{T}$ cells $\left(\mathrm{T}_{\mathrm{CM}}\right)$, remain controversial and have not been subjected to adequate study [13, 19, 20]. Considering the fact that the CAR $\mathrm{T}$ cells administered to patients may interact with components of the endogenous immune system in vivo [21], it will be important to resolve issues associated with expansion kinetics and to understand the functional capabilities of different $\mathrm{T}$ cell subsets during the course of treatment in order to identify potential biomarkers that will predict long-term responses.

In this research, we analyzed the kinetics of various $\mathrm{T}$ cell subsets collected from the peripheral blood of patients after CAR $\mathrm{T}$ cell infusion. Our findings suggest that the percentage of $\mathrm{CD}^{+}$naïve $\mathrm{T}$ cells $\left(\mathrm{T}_{\mathrm{N}}\right)$ represents a potential biomarker that might be developed as a means to predict the long-term prognosis of patients undergoing CAR T cell therapy.

\section{Methods}

Human CD19 structure and antibody homology modeling The crystal structure of human CD19 (hCD19) is publicly available (PDB ID: 6AL5). However, this structure is not the ECD of CD19. The CD19 3D structure was remodeling based on 6AL5 by using the "Create homology Models" program in Discovery Studio [22]. All models were ranked by PDF total energy. Choose the structure with the lowest PDF total energy for further modeling. This rough structure was analyzed using Ramachandran plot and "Profiles-3D Verify" program and then optimized using "Loop Refinement". The scFv homology models of HI19 $\alpha$ and FMC63 were generated based on their amino acid sequences, using the "Create homology 
Models" module in Discovery Studio [8]. The sequence of each antibody was searched in the structure database of PDB to find its best templates. All BLAST hits were ranked by $E$ value. Choose 5 templates with high resolution $(<2.8 \AA)$ for further modeling. One hundred models were constructed for each antibody. The final model was chosen based on its PDF total energy, Ramachandran plot and Profile-3D verify result.

\section{Antibody-antigen docking}

The binding mode between hCD19 and HI19 $\alpha$ (or FMC63) was performed by rigid body docking program ZDOCK and integrated in Discovery Studio. Keeping the position of antibody fixed as a receptor, the hCD19 model was rotated around the receptor in a rigid-body manner to search possible binding poses. Fifty-four thousand poses were generated after each ZDOCK and ranked by ZDOCK score. Only those poses with high ZDOCK score $(>12)$ were selected for further optimization. Furthermore, by knowing that CDR loops on antibodies are the roughly binding sites, additional filtering process was performed to narrow down the scope of refinement. All qualified poses were typed with the CHARMm Polar $\mathrm{H}$ forcefield and refined using $\mathrm{B}$ RDOCK program. Choose the final binding poses based on RDOCK scores and protein binding interface.

\section{The antibody competition experiment}

$1.3 \times 10^{5}$ Nalm- 6 cells were stained with $0.0112,0.0168$, 0.0336, 0.0420 , or $0.0672 \mathrm{pM} \mathrm{FMC63} \mathrm{for} 30 \mathrm{~min}$ at $4{ }^{\circ} \mathrm{C}$, respectively, washed twice, and then stained with 0.02 $\mu \mathrm{g} / \mu \mathrm{l}$ anti-mouse $\operatorname{IgG}(\mathrm{H}+\mathrm{L}), \mathrm{F}(\mathrm{ab})_{2}$ Fragment for 30 min at $4{ }^{\circ} \mathrm{C}$. $1.3 \times 10^{5}$ Nalm-6 cells were stained with $0.0068,0.0136,0.017,0.034$, or 0.068 pM HI19 $\alpha-\mathrm{PE}$ antibody for $30 \mathrm{~min}$ at $4{ }^{\circ} \mathrm{C}$, respectively. The minimum binding concentration of antibody was determined. Then, $1.3 \times 10^{5}$ Nalm- 6 cells were stained with 0.0420 pM FMC63 for $30 \mathrm{~min}$ at $4{ }^{\circ} \mathrm{C}$, washed twice, stained with $0.02 \mu \mathrm{g} / \mu \mathrm{l} \mathrm{F}\left(\mathrm{ab}^{\prime}\right)_{2}$-Alexa Fluor 647 for $30 \mathrm{~min}$ at 4 ${ }^{\circ} \mathrm{C}$, and washed twice. And then stained with $0.017 \mathrm{pM}$ HI19 $\alpha$-PE for 30 min at $4{ }^{\circ} \mathrm{C}$. After staining, all the cells were washed twice and suspended in PBS for flow cytometry analysis.

\section{Clinical trial design and patients}

We conducted an open-label, single-center, and singlearm pilot study to evaluate the safety and efficacy of CD19 CAR T cells derived from a new clone HI19 $\alpha$ into patients with $\mathrm{CD} 19^{+} \mathrm{R} / \mathrm{R}$ B-ALL at the Institute of Hematology \& Blood Diseases Hospital, Chinese Academy of Medical Sciences \& Peking Union Medical College. The patients were eligible if they were $C D 19^{+} R / R$ B-ALL who fail to achieve remission after first or more salvage treatment. Philadelphia chromosome (Ph)- positive B-ALL patients must have failed treatment with at least 1 second-generation tyrosine kinase inhibitor (ponatinib is unavailable in China) or with T315I mutation. Patients were excluded if they had an active central nervous system leukemia (CNSL) and insufficient performance status (Eastern Cooperative Oncology Group performance score $\geq 3$ ) or organ function. The primary and secondary objectives are the safety and efficacy of CNCT19 in childhood and adult patients with R/R BALL, respectively.

\section{CD19 CAR T construction and generation}

The CD19 CAR T cells were produced by Juventas Cell Therapy Ltd (Product ID: CNCT19). The scFv sequence specific for CD19 was derived from clone HI19 $\alpha$, which was established at our hospital. Anti-CD19 scFv combined to human $4-1 \mathrm{BB} / \mathrm{CD} 3-\zeta$ costimulatory signaling components were cloned into a lentiviral backbone to obtain lentiviral vectors pCDH-HI19 $\alpha-4-1 \mathrm{BB} / \mathrm{CD} 3 \zeta$ CAR. The lentivirus packaging and CAR $\mathrm{T}$ cell transduction and expansion were performed as described [11, 23]. In addition, CD19 CAR $T$ cultures were checked twice for possible contamination of fungus, bacteria, mycoplasma, chlamydia, and endotoxin and subsequently stored at $-80{ }^{\circ} \mathrm{C}$ until use.

\section{Clinical protocol design and assessment of toxic effects}

Prior to CAR $\mathrm{T}$ cell infusion, all patients underwent FAC lymphodepletion chemotherapy that included cyclophosphamide $\left(350 \mathrm{mg} / \mathrm{m}^{2} /\right.$ day, days -4 and -2$)$, fludarabine $\left(30 \mathrm{mg} / \mathrm{m}^{2} /\right.$ day, days $-4,-3$, and -2$)$, and cytarabine $\left(100 \mathrm{mg} / \mathrm{m}^{2} /\right.$ day, days $-4,-3,-2$, and -1$)$. No other treatments were administered, prescribed, or modified as part of this study. Total $\mathrm{T}$ cells were administered at a dosage of $5 \times 10^{6}$ cells per kilogram $(\mathrm{kg})$ of body weight. The median efficiency of the final CAR $\mathrm{T}$ cell transduction was 0.41; as such, the median CAR $\mathrm{T}$ cell concentration reached $2.02 \times 10^{6} / \mathrm{kg}$ body weight (range $0.75 \times$ $10^{6}-4.08 \times 10^{6}$ cells $/ \mathrm{kg}$ body weight) in this study. The patients underwent bone marrow (BM) examination on day 14 and day 28 to determine the remission status. CR rate and relapse were evaluated in accordance with the National Comprehensive Cancer Network (NCCN) guidelines, version 1.2016. Minimal residual disease (MRD) negative response is defined as less than $10^{-4}$. $\mathrm{BM}$ blasts are determined by flow cytometry assays. And no target amplification with a minimum sensitivity of $10^{-4}$ by quantitative real-time polymerase chain reaction in $\mathrm{Ph}^{+} \mathrm{B}$-ALL. The presence of CAR T cells and phenotype of $\mathrm{T}$ cells was detected and quantified using multiparameter flow cytometry in the peripheral blood from all patients. Surface marker staining was performed to assess the corresponding subpopulation markers on regulatory $\mathrm{T}$ cells (Tregs, $\mathrm{CD} 4^{+} \mathrm{CD} 25^{+} \mathrm{CD} 127^{-}$), naïve 
$\mathrm{T}$ cells $\left(\mathrm{T}_{\mathrm{N}}, \mathrm{CD}^{-} 5 \mathrm{RA}^{+} \mathrm{CCR7}^{+}\right)$, central memory $\mathrm{T}$ cells $\left(\mathrm{T}_{\mathrm{CM}}, \mathrm{CD} 45 \mathrm{RA}^{-} \mathrm{CCR}^{+}\right)$, effector memory $\mathrm{T}$ cells $\left(\mathrm{T}_{\mathrm{EM}}\right.$, CD45RA $\left.{ }^{-} \mathrm{CCR}^{-}\right)$, and effector $\mathrm{T}$ cells $\left(\mathrm{T}_{\mathrm{E}}, \mathrm{CD} 45 \mathrm{RA}^{+}\right.$ $\mathrm{CCR}^{-}$). The antibodies were listed in Supplementary Table 1. The cytokine release syndrome (CRS) was graded and managed according to Lee's grading system for CRS [24]. Grade of adverse event was evaluated over the whole duration of the treatment, an expected average of 24 months using the National Cancer Institute Common Terminology Criteria for Adverse Events (NCI-CTCAE) version 4.03 (https://ctep.cancer.gov/).

\section{Statistical analysis}

Overall survival (OS) was calculated from the date of enrolled to the date of death or last follow-up. Relapse-free survival (RFS) was calculated from the date of CR/CRi to the date of relapse or death, or the last follow-up. The independent $t$ test and Mann-Whitney non-parametric test was used for the analysis of continuous variables. The chi-square test was used for categorical data. The probabilities of OS and RFS were estimated by means of the Kaplan-Meier. Both univariate and multivariable Cox regression analyses were applied to determine whether the $\mathrm{T}$ cell percentage contributed to the long-term response. All $p$ values represented were two-sided and considered statistically significant when $p<0.05$. Statistical analyses were performed with SPSS 19.0 software.

\section{Results}

\section{FMC63 scFv and HI19a scFv detect distinct epitopes} within the extracellular domain of CD19

Currently, the scFv derived from hybridoma clone FMC63 is typically incorporated into targeted CD19 CAR T cell products. Here, we generated novel CD19 CAR T cells with the scFv derived from novel hybridoma HI19 $\alpha$. To determine whether these two different scFvs detect distinct epitopes on hCD19, the structure of the hCD19 ECD, the FMC63 scFv, and the HI19 $\alpha$ scFv were evaluated by molecular modeling (Fig. 1a). The binding interactions between hCD19 and HI19 $\alpha$ and hCD19 and FMC63 were evaluated by the rigid body docking program ZDOCK; the findings were integrated with Discovery Studio (Fig. 1b, c). The amino acids of hCD19 ECD predicted to be involved in binding interactions are shown in Fig. 1d (gray background). Our initial results revealed that the hCD19 epitopes detected by the two scFvs were not identical. To identify the key antigen epitopes, alanine scanning mutagenesis was performed at the binding interface for each complex (Fig. 1d). After the introduction of each mutation, an increase in binding energy by $>0.5$ was used to identify the critical amino acid residues (Fig. 1d; Supplementary Tables 2 and 3). The results revealed an overlap between the critical amino acid residues involved in the interactions between the HI19 $\alpha$ scFv and the FMC63 scFv with the hCD19 ECD (Fig. 1d). The interaction between each of the scFvs and the hCD19 ECD involved noncovalent bonds (Supplementary Tables 4 and 5); partial interaction modes are as shown in Fig. 1e. To verify the findings from the docking model, minimum binding concentrations of each of the two scFvs were determined in an experiment targeting Nalm-6 cells; nearly all of these cells express CD19 (Fig. 1f). The minimum binding concentrations of the FMC63 and HI19 $\alpha$ scFvs were 0.042 and $0.017 \mathrm{pM}$, respectively. Antibody competition experiments were also performed; the results revealed that Nalm- 6 cells could be detected simultaneously with both antibodies (Fig. 1g). These results provided further confirmation that the FMC63 and HI19 $\alpha$ scFvs interacted with distinct epitopes within the hCD19 ECD.

\section{Characteristics and response rates of patients diagnosed with R/R B-ALL}

To assess the safety and feasibility of CNCT19 cell therapy in patients with R/R B-ALL, 24 childhood and adult were screened from January 6, 2017, through August 12, 2019; two patients were not enrolled in the study for the reasons listed in Supplementary Fig. 1. A total of 22 patients undergo an attempt at CAR T production; two of whom did not have cells infused (one owing to drawing consent, one because of production failure). As such, a total of 20 patients received an infusion of CAR T cells. At enrollment, these patients were at the median age of 18 years old (range, 3-52 years old). The median percentage of abnormal B cells in BM specimens from these 20 patients prior to lymphodepletion chemotherapy was $35.5 \%$ (range, 3-96\%); two patients had both BMassociated and extramedullary disease (Table 1). Complex chromosomal aberrations, including high-risk fusions and mutations including TP53 and IKZF1 deletions, were identified in $8(40 \%)$ patients. The rate of CR/CRi achieved by the 20 patients who received CAR $\mathrm{T}$ cell infusion was $90 \%$ at day 28 (Fig. 2). In a further intention-to-treat analysis of the full enrolled 22 patients, the CR/CRi rate at day 28 was $82 \%$. After infusion of CNCT19 cells, two patients died within 28 days due to CAR T cell-related encephalopathy syndrome (CRES); the 18 surviving patients achieved MRD-negative remission (100\%) within 3 months. The two patients with extramedullary disease in the lumbar spine or skin also achieved CR; this was confirmed in BM aspirates, skin biopsies, and computed tomography scans. Taken together, these results demonstrate that CD19 CAR T cell therapy with CNCT19 cells results in a rapid induction of CR that is effective for patients diagnosed with R/R BALL involving both BM and in extramedullary sites. This therapeutic option is effective in patients with complex chromosomal aberrations, including high-risk gene fusions and mutations. 


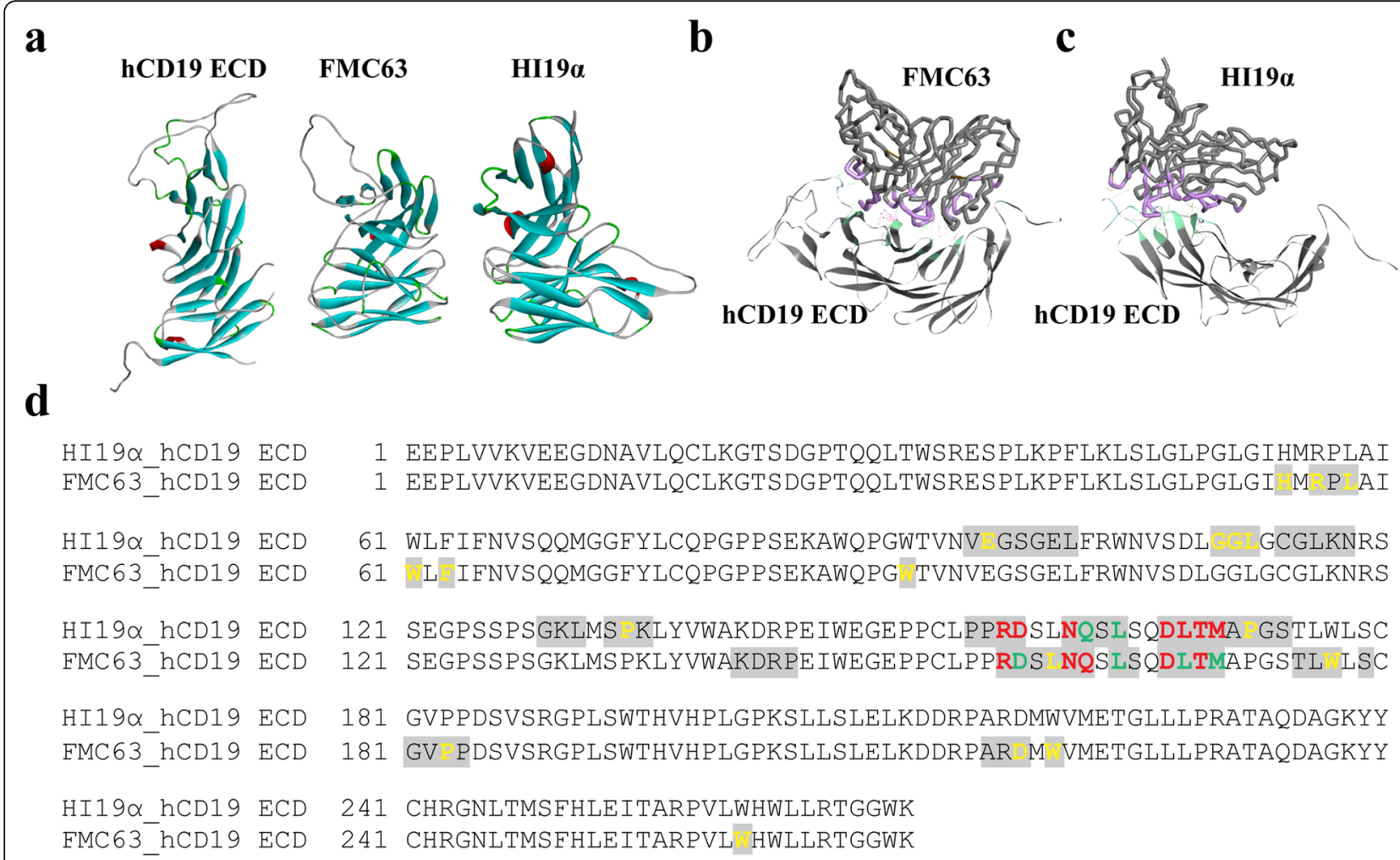

$\mathbf{e}$

HI19 $\alpha$ and hCD19 ECD

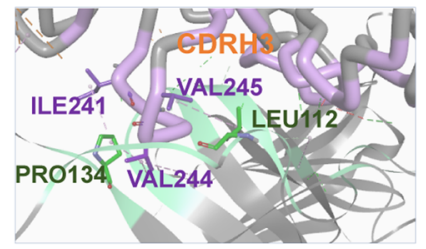

FMC63 and hCD19 ECD

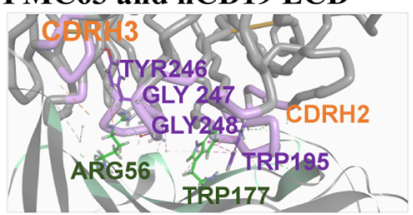

\section{$\mathbf{f}$}

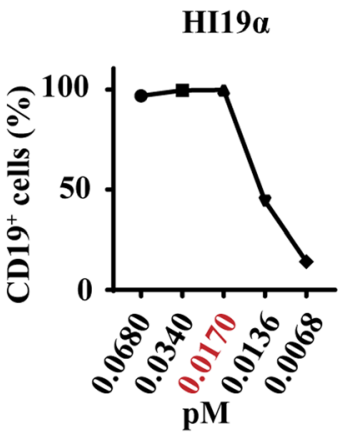

FMC63

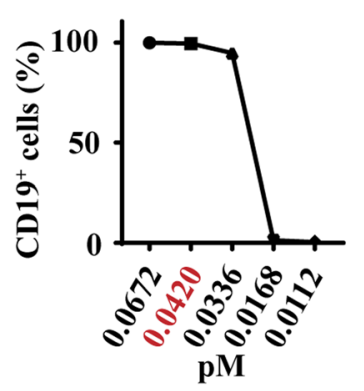

g

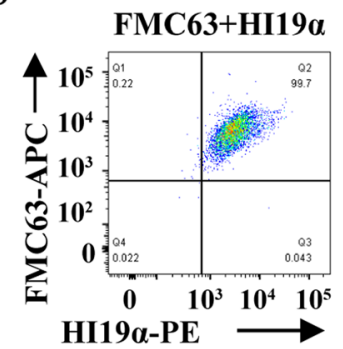

Fig. 1 FMC63 and HI19a had different binding epitopes on CD19. a Homology models of hCD19 ECD (left), FMC63 scFV (middle), and HI19a scFV (right). b Docking mode of FMC63 and hCD19 ECD. Green, hCD19 ECD epitopes; purple, FMC63 epitopes. c Docking mode of HI19a and hCD19 ECD. Green, hCD19 ECD epitopes; purple, HI19a epitopes. d Sequence of hCD19 ECD. Gray background, predicted binding amino acid residues on hCD19 ECD with scFvs. Upper panel, interaction with H119a; lower panel, interaction with FMC63. Red color, shared antigen epitopes; yellow color, key epitopes; green color, both shared antigen epitopes and key epitopes. e Partial interaction modes showed the non-bond interaction between scFvs and hCD19 ECD. Upper panel, HI19a scFv and hCD19 ECD; lower panel, FMC63 scFv and hCD19 ECD. Green, hCD19 ECD epitopes; purple, scFvs epitopes. $\mathbf{f}$ Flow cytometry analysis of the proportion of CD19+ Nalm- 6 cells stained with indicated concentrations of the antibody. Left panel, HI19a antibody; right panel, FMC63 antibody. g Representative flow cytometry analysis showing the proportion of CD19+ cells on Nalm-6 cells stained with 0.017 pM HI19a and 0.042 pM FMC63

\section{Long-term survival}

A total of 11 patients did not survive to the median follow-up time of 10.09 months (range, 0.49-24.02 months); as noted earlier, this included the two patients who developed CRES within 28 days of the infusion, as well as six who experienced relapse and disease progression, and three who experienced complications associated with hematopoietic stem cell transplantation (HSCT). The median OS reached 12.91 months (95\% confidence interval [CI], 7.74-18.08 months; Fig. 3a) for 
Table 1 Clinical characteristics of 20 R/R B-ALL patients

\begin{tabular}{|c|c|c|c|c|c|c|c|c|}
\hline $\begin{array}{l}\text { Patient } \\
\text { number }\end{array}$ & Age & Gender & ECOG & Leukemia type and genetic abnormalities & $\begin{array}{l}\text { Disease } \\
\text { status }\end{array}$ & $\begin{array}{l}\text { BM blasts } \\
\text { burden }\end{array}$ & $\begin{array}{l}\text { Prior lines of } \\
\text { treatment }\end{array}$ & $\begin{array}{l}\text { EMD } \\
\text { status }\end{array}$ \\
\hline 1 & 31 & Female & 1 & Ph-ALL & Refractory & $56.0 \%$ & 2 & No \\
\hline 2 & 23 & Female & 1 & $\mathrm{Ph}+\mathrm{ALL} *(T 315 \mathrm{I}$ mutation $)$ & Relapse & $38.6 \%$ & 2 & No \\
\hline 3 & 50 & Male & 0 & Ph-ALL & Refractory & $3.0 \%$ & 2 & No \\
\hline 4 & 18 & Male & 0 & Ph-ALL & Relapse & $30.5 \%$ & 2 & No \\
\hline 5 & 44 & Male & 0 & Ph-ALL & Refractory & $24.5 \%$ & 2 & No \\
\hline 6 & 16 & Male & 0 & Ph-ALL (IKZF1 deletion, NRAS mutation) & Refractory & $26.0 \%$ & 3 & No \\
\hline 7 & 10 & Male & 0 & Ph-ALL (E2A-PBX1 rearrangement) & Relapse & $4.5 \%$ & 2 & No \\
\hline 8 & 16 & Male & 0 & Ph+ALL (T315I mutation) & Relapse & $83.5 \%$ & 2 & No \\
\hline 9 & 24 & Male & 1 & Ph-ALL & Relapse & $40.5 \%$ & 2 & No \\
\hline 10 & 9 & Male & 0 & Ph-ALL (IgH rearrangements) & Refractory & $40.5 \%$ & 2 & No \\
\hline 11 & 7 & Male & 0 & Ph-ALL & Relapse & $7.5 \%$ & 2 & No \\
\hline 12 & 9 & Female & 0 & Ph-ALL (ETV6-RUNX1 rearrangement) & Relapse & $10.0 \%$ & 2 & No \\
\hline 13 & 19 & Male & 0 & $\begin{array}{l}\text { Ph-like ALL (EBF1-PDGFRB rearrangement, IKZF1 } \\
\text { deletion) }\end{array}$ & Relapse & $75.0 \%$ & 2 & Yes \\
\hline 14 & 14 & Female & 0 & Ph-ALL & Refractory & $32.5 \%$ & 3 & No \\
\hline 15 & 18 & Male & 0 & $\begin{array}{l}\text { Ph-like ALL (PAX5-JAK2 rearrangement, TP53 } \\
\text { deletion) }\end{array}$ & Relapse & $73.5 \%$ & 1 & No \\
\hline 16 & 43 & Female & 1 & Ph-ALL & Refractory & $60.5 \%$ & 2 & No \\
\hline 17 & 11 & Female & 0 & Ph-ALL & Refractory & $5.0 \%$ & 2 & No \\
\hline 18 & 3 & Female & 0 & Ph-ALL (TP53 mutation, IKZF1 deletion) & Refractory & $6.0 \%$ & 5 & No \\
\hline 19 & 52 & Female & 0 & Ph-ALL & Refractory & $96.0 \%$ & 2 & No \\
\hline 20 & 40 & Male & 0 & Ph-ALL (IKZF1 deletion) & Refractory & $64.5 \%$ & 2 & Yes \\
\hline
\end{tabular}

$E M D$ extramedullary disease, $P h$ Philadelphia chromosome

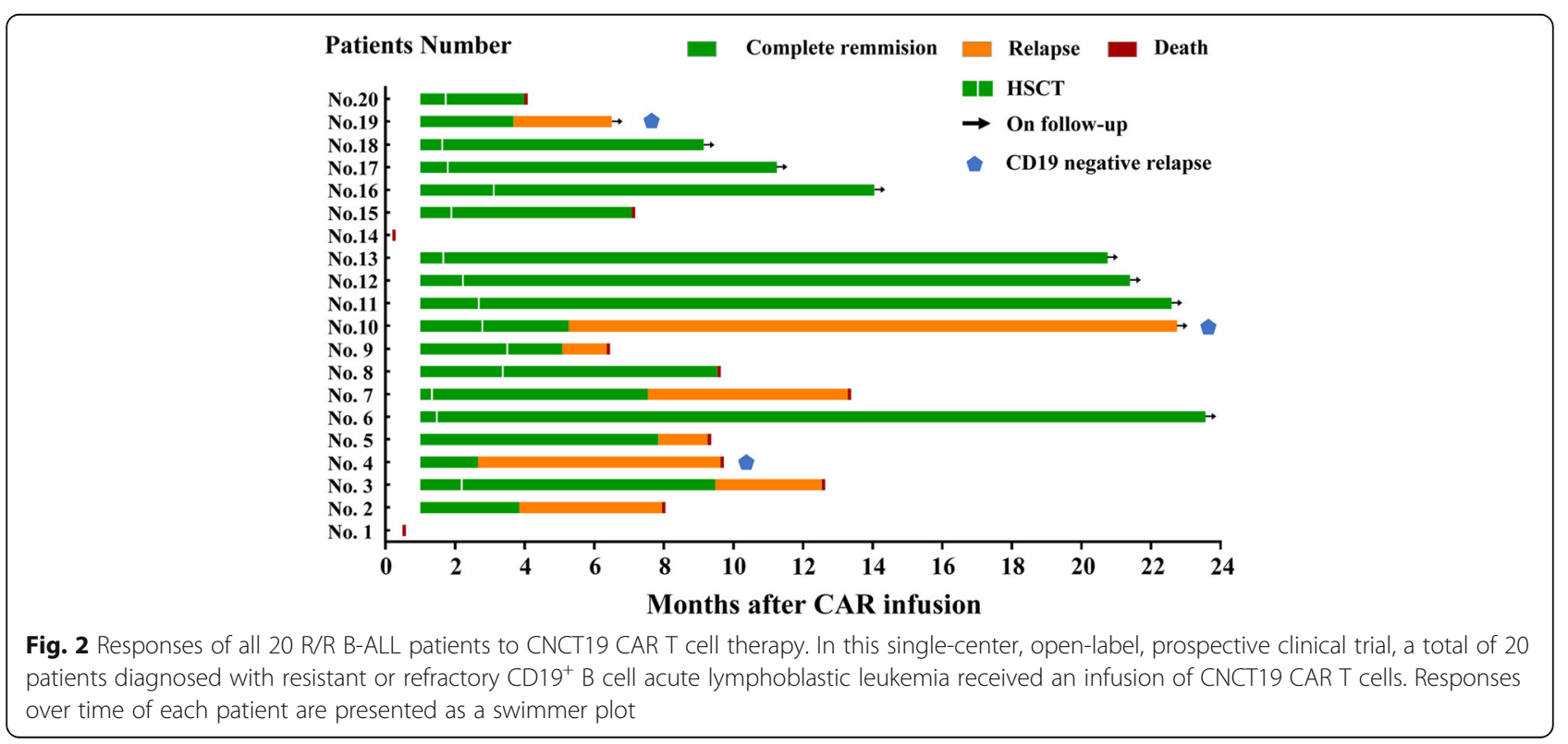




\section{a}

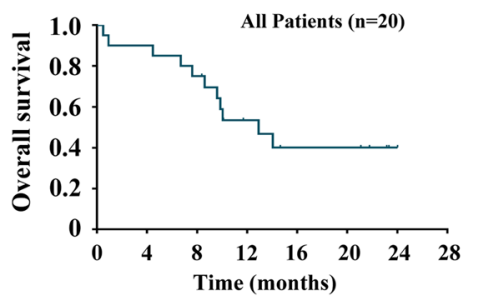

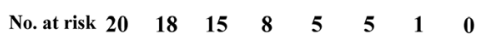

c
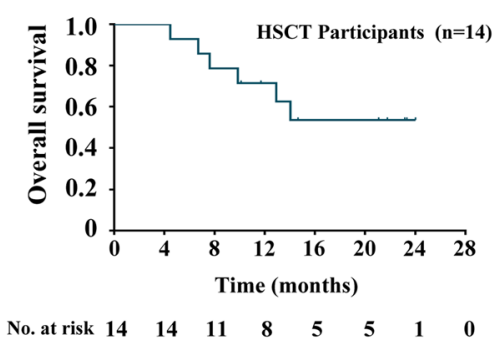

e

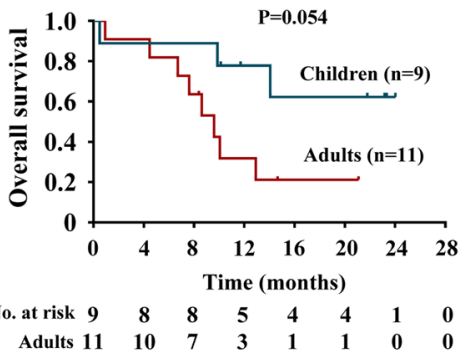

b

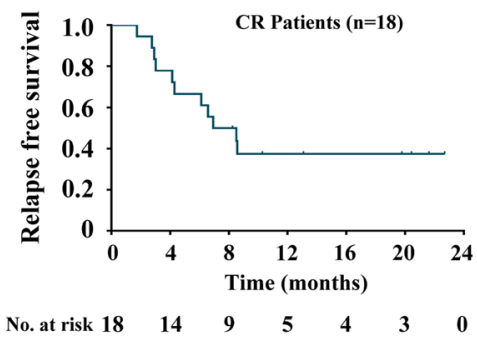

d

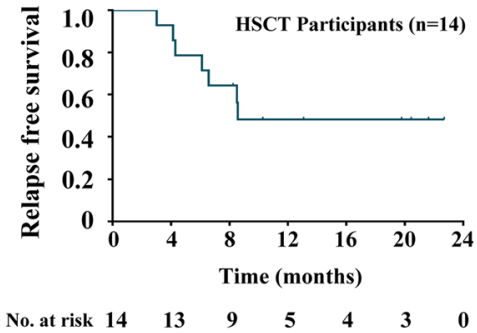

f

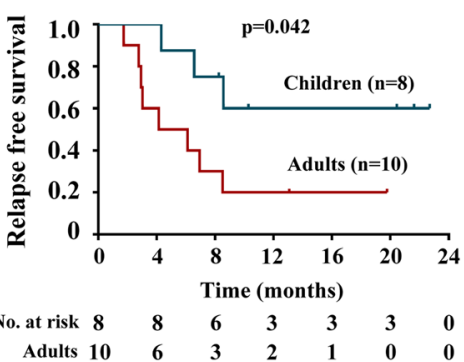

Fig. 3 Long-term survival. a-b Overall survival (a) and relapse-free survival (b) of the 20 R/R B-ALL patients treated with the CNCT19 CAR T cell infusion. Overall survival (c) and relapse-free survival (d) of patients who underwent hematopoietic stem cell transplantation. Overall survival (e) or relapse-free survival (f) of both pediatric and adult patients

the patients who received CAR $\mathrm{T}$ cell infusion. Among the 18 patients who achieved CR, eight patients eventually relapsed; five of these relapses involved CD19positive cells and three were CD19-negative. There were no central nervous system-associated relapses in this patient cohort. The median RFS for the entire patient cohort was 6.93 months (95\% CI, 3.13-10.73 months; Fig. 3b). Fourteen patients underwent allogeneic HSCT after treatment with the CD19 CAR T cell infusion. The median time from the CAR T cell infusion to HSCT was 61 days (range, 40-106 days). The median OS for patients who underwent allogeneic HSCT was not reached. Oneyear OS rate and RFS rate of patients who bridge to allogeneic HSCT after CAR T cell therapy was $62.2 \%$ (95\% $\mathrm{CI}, \quad 31.2-82.4 \%)$ and $49.2 \%$ (95\% CI, 21.9-71.7\%), respectively (Fig. 3c, d). Childhood (age $<18$ years old) experienced longer OS and RFS than did the adult patients ( $p=0.054$ and 0.042 , respectively), although these differences did not reach statistical significance on OS (Fig. 3e, f).
T cell phenotypes and correlation with long-term survival In an effort to identify factors associated with the long-term response to therapy, we assessed the CD19 CAR $\mathrm{T}$ cell percentages and $\mathrm{T}$ cell phenotypes in peripheral blood by flow cytometry at serial time points after the CAR $\mathrm{T}$ cell infusion. We found that CAR $\mathrm{T}$ cells can be detected in the blood for up to 235 days after infusion (Fig. 4a); the greatest expansion of these cells was detected at day 14 among the 20 patients who received CAR $\mathrm{T}$ cell infusion as part of this trial. After CD19 CAR T cell infusion, we detected a gradual decrease in the fraction of $\mathrm{CD}_{4}^{+} \mathrm{T}$ cells accompanied by a significant increase in the percentage of $\mathrm{CD}^{+} \mathrm{T}$ cells (Fig. 4b). Further evaluation of these $\mathrm{T}$ cell subsets revealed gradual reductions in the percentages of both $\mathrm{CD}^{+}$and $\mathrm{CD}^{+} \mathrm{T}_{\mathrm{N}}$ (naïve) and $\mathrm{T}_{\mathrm{CM}}$ (central memory) cells after CD19 CAR $\mathrm{T}$ cell infusion. Percentages of both $\mathrm{CD}^{+} \mathrm{T}_{\mathrm{EM}}$ (effector memory) and $\mathrm{T}_{\mathrm{E}}$ (effector) cells increased significantly during the first 2 weeks after infusion; these 

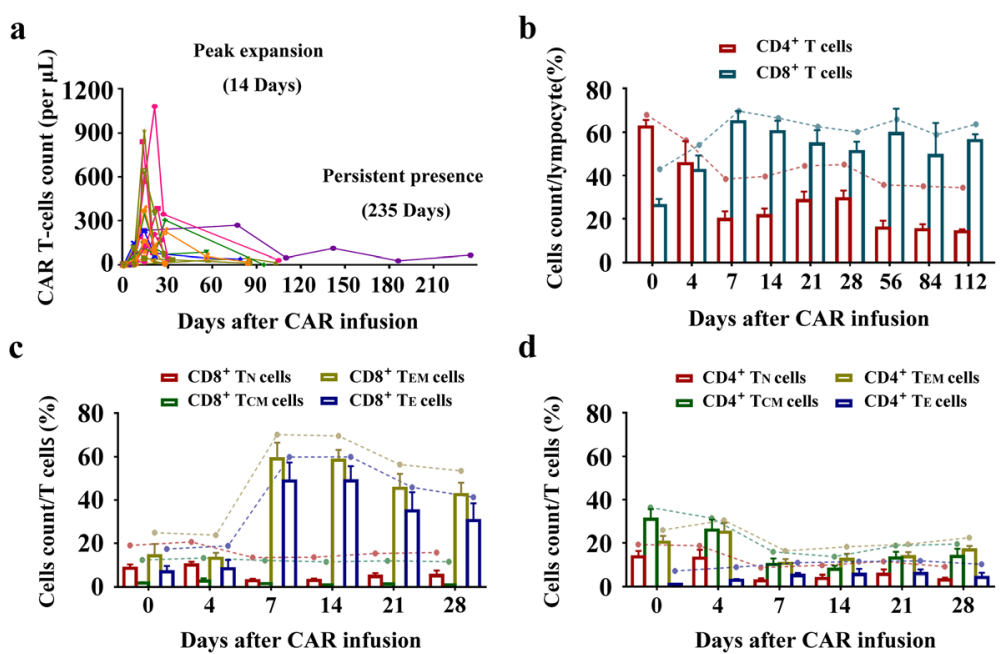

Fig. 4 The expansion kinetics of CAR T cells and different T cell subsets after CD19 CAR T cell infusion. a The expansion and persistence of CNCT19 CAR T cells after infusion. $\mathbf{b}$ The expansion and percentage of $C D 4^{+}$or $C D 8^{+} T$ cells in peripheral blood after CAR infusion. c-d The phenotype of $\mathrm{CD}^{+} \mathrm{T}$ cells $(\mathbf{c})$ or $\mathrm{CD}^{+} \mathrm{T}$ cells $(\mathbf{d})$ in peripheral blood after CNCT19 CAR T cell infusion $\left(T_{N}\right.$, naïve $T$ cells; $T_{C M}$, central memory $T$ cells; $T_{E M}$, effective memory $T$ cells; and $T_{E}$, effector $T$ cells)

percentages then decreased gradually, while the percentages of $\mathrm{CD}^{+} \mathrm{T}_{\mathrm{EM}}$ and $\mathrm{T}_{\mathrm{E}}$ cells were maintained at relatively stable levels (Fig. 4c, d). These results suggest that the $T_{N}$ and $T_{C M}$ cells may undergo gradual differentiation into $T_{E M}$ and $T_{E}$ cells that are the critical mediators of $\mathrm{CD} 19^{+}$cell death. Interestingly, we identified a significantly reduced percentage of $\mathrm{CD}^{+} \mathrm{T}_{\mathrm{N}}$ cells shortly after the CD19 CAR $\mathrm{T}$ cell infusion in patients who eventually relapsed from BALL compared to that in patients identified as longterm responders $(p=0.006$; Fig. 5a). Similarly, the percentage of $\mathrm{CD} 4^{+} \mathrm{T}_{\mathrm{N}}$ cells detected shortly after the CD19 CAR T cell infusion was lower in patients who ultimately experienced relapse, although these differences did not reach statistical significance (Fig. $5 b)$. No differences in the percentages of $T_{C M}, T_{E M}$, or $\mathrm{T}_{\mathrm{E}}$ cells were detected at any of the time points evaluated (Supplementary Fig. 2). To explore the relationship between the percentage of $\mathrm{T}_{\mathrm{N}}$ cells and the likelihood of relapse, we ranked and divided the $\mathrm{CD}^{+} \mathrm{T}_{\mathrm{N}}$ cells percentages detected in each patient shortly after CD19 CAR $T$ cell infusion into four quartiles, from lowest (Q1) to highest (Q4). The patients with $\mathrm{CD}^{+} \mathrm{T}_{\mathrm{N}}$ cell percentages in Q1 experienced shorter periods of RFS ( $p=0.004$; Fig. $5 \mathrm{c}$ ), although no association with OS was detected ( $p=$ 0.384; Fig. 5d). To confirm the outcomes and adjust for potential confounding factors, we constructed multivariate Cox models to test the proportional hazards assumption as well as the interaction terms with covariates. The variables included in the Cox models were those associated with $p$ values $<0.1$ in univariate analyses (Supplementary Table 6). The multivariate analysis indicated that the percentage of $\mathrm{CD}^{+} \mathrm{T}_{\mathrm{N}}$ cells emerged as an independent negative prognostic factor with respect to RFS ( $p=0.012$, 95\% CI, $0.017-$ 0.601; Supplementary Table 7). The percentage of $\mathrm{CD}^{+}{ }^{+} \mathrm{T}_{\mathrm{N}}$ cells detected shortly after CD19 CAR T cell infusion was not found to be associated with a shorter period of RFS or OS ( $p=0.173$ and 0.125 , respectively; Fig. 5e, f). Although the fraction of Tregs also increased in response to CD19 CAR T cell infusion (Supplementary Fig. 3a), no changes in the percentages of $\mathrm{CD}^{+} \mathrm{CD}^{2} 6^{+} \mathrm{CD} 16^{+} \mathrm{NK}$-like $\mathrm{T}$ cells or NK cells were observed (Supplementary Fig. 3b); this is intriguing, given the recent reports focused on NK cells and their unexpected regulatory role in outcomes associated with BM transplantation.

The fraction of $\mathrm{CD} 19^{+} \mathrm{B}$ cells was evaluated as a means to track potential relapse of B-ALL. After CD19 CAR $\mathrm{T}$ cell infusion, $\mathrm{CD} 19^{+} \mathrm{B}$ cells were eliminated within 3 months in 18 of the 20 patients. Interestingly, although relapses were detected in most patients within 5-20 days after the appearance of circulating $\mathrm{CD} 19^{+} \mathrm{B}$ cells, relapse in two patients was delayed to $>130$ days after $\mathrm{CD} 19^{+} \mathrm{B}$ cell detection (Supplementary Fig. 4a, b); of note, relapse occurred despite persistence of CD19 CAR T cells for $>180$ days in peripheral blood or BM in both of these patients.

\section{Toxicities associated with CNCT19 CAR T cell therapy}

The safety analysis set included all 20 patients who received an infusion of CNCT19 cells. The most significant treatment-related toxicities were CRS and CRES. Overall, the CRS was detected in 95\% (19/20) patients and was severe (grade $\geq 3$ ) in 9/20 (45\%). 
a
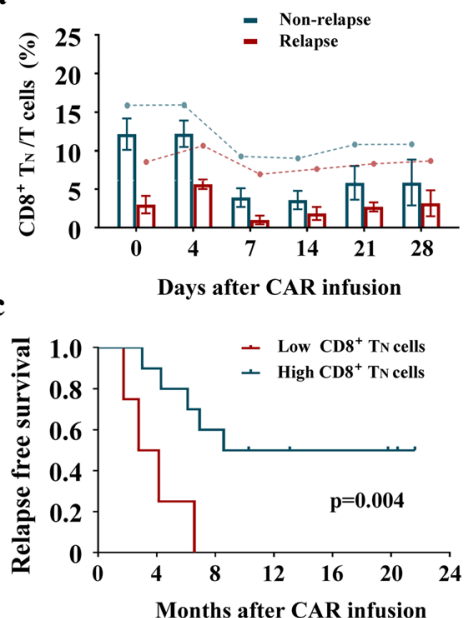

e

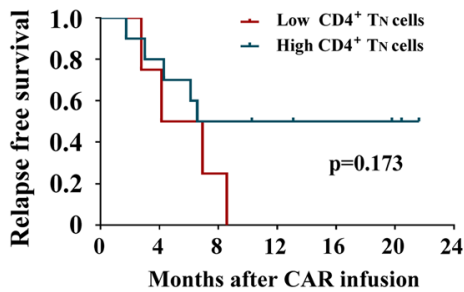

b
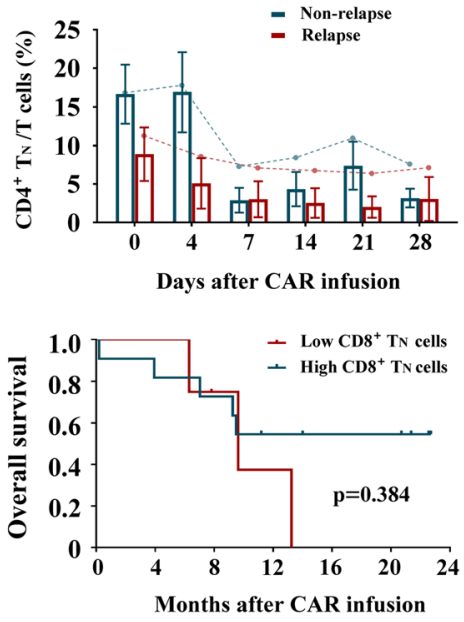

f

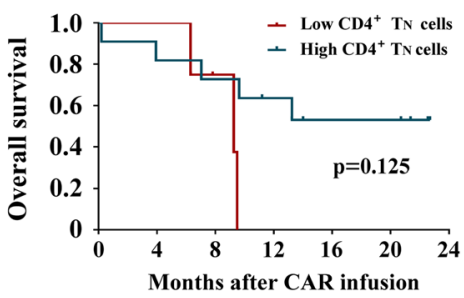

Fig. 5 The correlation between $T_{N}$ cell percentage and long-term survival. a, b Comparison of $C D 8^{+} T_{N}$ cells $(\mathbf{a})$ or $C D 4^{+} T_{N}$ cell (b) percentage in peripheral blood at different time points after CAR T cell infusion between long-term response and relapsed patients ( $T_{N}$, naïve $T$ cells). CD8 ${ }^{+}$or $\mathrm{CD}^{+} \mathrm{T}_{\mathrm{N}}$ cells percentage were ranked and divided into four quartiles, from lowest (Q1) to highest (Q4). $\mathbf{c}$, d Relapse-free survival (c) or overall survival (d) difference between patients with low $C D 8^{+} T_{N}$ cells percentage (Q1) and those with high $C D 8^{+} T_{N}$ cells percentage (Q2-4). e, $\mathbf{f}$ Relapse-free survival (e) or overall survival (f) difference between patients with low $C D 4^{+} T_{N}$ cells percentage (Q1) and high $C D 4^{+} T_{N}$ cells percentage (Q2-4)

The median onset of CRS was 4 days after the CAR $\mathrm{T}$ cell infusion; this complication lasted for an average duration of 8 days. The clinical signs and symptoms of CRS include fever, nausea, vomiting, hypotension, hypoxemia, and musculoskeletal pain. Hypofibrinogenemia, hyperbilirubinemia, and elevated levels of liver aminotransferases were the most common severe toxicities detected in association with specific organ systems, including six patients (30\%) with grade 3 hypofibrinogenemia that resolved within 2 months after the CAR $\mathrm{T}$ cell infusion. One patient (5\%) experienced grade 3 hyperbilirubinemia, and another patient $(5 \%)$ developed grade 3 elevations in liver aminotransferases. No severe abnormalities associated with renal or cardiovascular functions were observed (Table 2). CRES was diagnosed in 13 patients (65\%); eight of these patients experienced grade $\geq 3$ CRES, while two patients reached grade 5 . The most common neurologic events associated with CRES were headache $(20 \%)$, confusion $(5 \%)$, delirium $(20 \%)$, agitation (20\%), and seizures (20\%). The signs and symptoms associated with CRES were relieved by dexamethasone treatment. Furthermore, and as anticipated, all patients responded to CAR $\mathrm{T}$ cell infusion with reversible hematologic toxicity; four patients developed grade 3 infections although none experienced severe bleeding.

\section{Discussion}

A growing body of evidence has confirmed the high clinical efficacy of CAR $T$ cells that target CD19, notably for the treatment of B cell-associated hematological malignancies [1, 25-29]. Unfortunately, patients treated with CAR $\mathrm{T}$ cells remain prone to relapse; some of them may be mediated by mutations that develop in the tumor cell epitope which impair binding interactions with specific CAR $\mathrm{T}$ cell scFv $[9,10]$. Recent clinical trials seeking to improve the response to CAR $\mathrm{T}$ cell therapy have included numerous changes, ranging from modification of the costimulatory domain to varying the treatment regimen; however, the CAR $\mathrm{T}$ scFv used in these trials remain primarily those derived from hybridoma clones FMC63 or SJ25C1. Here, we report the safety and efficacy of infusions performed with CD19 CAR T cells derived from a new hybridoma clone HI19 $\alpha$ with scFvs that target distinct epitopes of hCD19 antigen. Data 
Table 2 Summary of adverse events in the 20 patients receiving CAR T cell infusion

\begin{tabular}{|c|c|c|c|}
\hline TEAEs $(\boldsymbol{N}=20)$ & Any grade (\%) & Grades 3-4 (\%) & Grade $5(\%)$ \\
\hline Cytokine release syndrome & 95 & 45 & 0 \\
\hline Neurologic event & 65 & 30 & 10 \\
\hline \multicolumn{4}{|l|}{ Hematologic event } \\
\hline Thrombocytopenia & 95 & 90 & 0 \\
\hline Anemia & 100 & 70 & 0 \\
\hline Neutropenia & 100 & 100 & 0 \\
\hline \multicolumn{4}{|l|}{ Non-hematologic event } \\
\hline Diarrhea & 50 & 0 & 0 \\
\hline Abdominal pain & 15 & 0 & 0 \\
\hline Insomnia & 5 & 0 & 0 \\
\hline Headache or dizziness & 20 & 0 & 0 \\
\hline Muscle or bone pain & 25 & 0 & 0 \\
\hline Capillary leak syndromes & 30 & 0 & 0 \\
\hline Infection & 20 & 20 & 0 \\
\hline Hypotension & 25 & 5 & 0 \\
\hline Hypoxemia & 30 & 5 & 0 \\
\hline Elevated aminotransferases & 60 & 5 & 0 \\
\hline Elevated blood bilirubin & 60 & 5 & 0 \\
\hline Elevated creatinine & 0 & 0 & 0 \\
\hline Cardiovascular disorders & 0 & 0 & 0 \\
\hline Hyponatremia & 20 & 0 & 0 \\
\hline Hypokalemia & 55 & 0 & 0 \\
\hline Hypocalcemia & 65 & 0 & 0 \\
\hline Hypoalbuminemia & 50 & 0 & 0 \\
\hline Hypofibrinogenemia & 60 & 30 & 0 \\
\hline Prolonged activated partial thromboplastin time & 15 & 0 & 0 \\
\hline
\end{tabular}

from our study suggested that $90 \%$ of patients achieved $\mathrm{CR} / \mathrm{CRi}$ within 28 days after the CAR $\mathrm{T}$ cell infusion, which accounted for $82 \%$ of the fully enrolled 22 patients in an intention-to-treat analysis; these values are comparable to those obtained in the pivotal ELIANA study, which included an overall remission rate of $81 \%$ in patients receiving CAR $\mathrm{T}$ cell infusion and $66 \%$ when accounting for all fully enrolled patients [30]. The median OS and RFS in response to CNCT19 cells infusion were similar to findings published previously, including those observed in response to 19-28 CAR T cells generated at the Memorial Sloan Kettering Cancer Center (MSKCC), New York, USA (i.e., median OS of 12.9 vs. 12.9 months and median RFS of 6.9 vs. 6.1 months) [12]. Our results suggest that the CD19 CAR T cells derived from the HI19 $\alpha$ clone are also capable of promoting high anti-leukemic efficacy and may be able to address issues associated with poor prognosis in R/R B-ALL patients. Nonetheless, our results need to be interpreted with caution because 14 of the 20 patients in our study underwent subsequent consolidation with HSCT; this fraction was much higher than reported among the patients in the MSKCC's trial (17/53) and may play a significant role in maintaining the long-term response to treatment [30]. As such, the duration of the response associated specifically with CNCT19-based T cell therapy requires further investigation. In addition, while CARs with alternative targets and humanized CD19-CAR have been reported to be attractive in addressing the $\mathrm{CD} 19^{+}$ relapse after CD19-CAR T cell therapy [31,32], whether CNCT19 could provide an alternative choice for those patients, especially in patients with $\mathrm{CD} 19^{+}$relapse from CAR $T$ therapy based on the clone FMC63, is still worthy of research. And before exploring that issue, humanized modification of CNCT19 may be necessary considering the potential immune-mediated rejection on the murine origin domains of CAR T cells $[29,33]$.

Although CNCT19 cells are therapeutically effective in patients with R/R B-ALL, the associated toxicities, which occurred in all studies featuring infusions of CAR $T$ 
cells, remain a significant concern. In our study, highgrade CRS developed in $45 \%$ of patients after CNCT19 cells infusion; this result is similar to that observed in the ELIANA study, in which severe CRS was reported in $47 \%$ of the children and young adults with R/R B-ALL who were treated with tisagenlecleucel [30]. Severe CRS associated with CNCT19 T cells infusion was observed predominantly among patients with high tumor burden; severe CRS developed in $85.7 \%$ (6/7) of patients with $50 \%$ or more BM blasts, but only in $23 \%(3 / 13)$ of the patients with fewer than $50 \%$ blasts in the BM. This is consistent with results reported by Maloney et al. [29], which discussed the role of tumor burden and the associated risks of severe CRS and neurotoxicity. These results highlight the need to decrease the tumor burden prior to the CAR T cell infusion. Of note, CNCT19 cells seem to be associated with relatively high rate of severe neurotoxicity; $40 \%$ of the patients receiving CNCT19 cells infusion experienced severe neurotoxic complications, compared with $13 \%$ in the ELIANA study. The mechanisms underlying the observed neurotoxic responses to CAR $\mathrm{T}$ cell therapy remain unclear. According to previously published data, severe CAR T cellassociated neurologic events were reported in 5-21\% of children and young adults $[2,26,30]$ and in $\sim 42-$ $50 \%$ of adult patients with R/R B-ALL $[12,29]$. Severe neurotoxicity appears to be more commonplace among adult patients, although the heterogeneity with respect to the specific CAR T cell preparations as well as the characteristics of the patients enrolled in each study do not permit direct comparisons to be performed. The analyses from MSKCC also suggested a possible association between neurotoxicity with the age of the patients, although these results did not reach significance [12]. In light of this, the relatively older age of the patients enrolled in our trial may provide a partial explanation for the higher incidence of neurotoxicity observed here than ELIANA study. Furthermore, differences with respect to lymphodepletion strategies and expansion kinetics associated with CAR $\mathrm{T}$ cells may also influence their overall safety profiles. To the best of our knowledge, we describe here the first clinical trial that features an FAC regimen (fludarabine, cytarabine, cyclophosphamide) for lymphodepletion prior to CAR $\mathrm{T}$ cell infusion. While more aggressive lymphodepletion may help promoting the initial expansion and efficacy of CAR $\mathrm{T}$ cells by diminishing the regulatory mechanisms and increasing the availability of homeostatic cytokines, we cannot rule out the possibility that rapid and extensive expansion of the CAR $T$ cell population may result in an accelerated release of proinflammatory cytokines and an increased incidence of severe adverse events [34-36]. Meanwhile, aggressive lymphodepletion may result in broad impairment of normal tissues and endothelial activation, which may also ultimately trigger a higher incidence of severe toxicity [36, 37]. As such, additional studies will be needed to explore the impact of various lymphodepletion regimens with respect to the efficacy vs. the toxicity associated with adoptive $T$ cell therapy. It will be critical to develop one or more lymphodepletion strategies that optimally balance the risk and benefit for the patients. And more importantly, several safety strategies of CAR $\mathrm{T}$ cells, including suicide genes, on-switch CAR, combinatorial target-antigen recognition, and bispecific $\mathrm{T}$ cell engager have been developed to reduce the side effects, which may provide a great opportunity toward improving the safety of CNCT19 [38].

Recent studies that have explored various other factors associated with relapse after HSCT have focused on the differential expansion of $\mathrm{T}$ cell subsets. It was initially presumed that a comparatively high level of $\mathrm{T}_{\mathrm{E}}$ cells, which demonstrate immediate cytolytic capabilities, would correlate with long-term anti-tumor activity. However, emerging data from preclinical studies suggest that terminally differentiated $\mathrm{T}$ cell subsets display impaired anti-tumor responses in vivo $[39,40]$ and that a high percentage of one or more subsets of less differentiated $\mathrm{T}$ cells may contribute to the prolonged in vivo persistence of functional CAR T cells [14, 19, 41]. Further research has revealed that human $\mathrm{CD}^{+} \mathrm{T}$ cells derived from less differentiated subsets, such as $\mathrm{T}_{\mathrm{N}}$ cells $[42,43]$, exhibit superior traits with respect to adoptive immunotherapy; the anti-tumor capacities of $\mathrm{CD}^{+} \mathrm{T}$ cells derived from $\mathrm{T}_{\mathrm{CM}}$ subsets remain still controversial and poorly understood $[43,44]$. Future studies will be needed to determine the role(s) played by expansion kinetics of various $\mathrm{T}$ cell subsets with respect to long-term survival of patients undergoing CD19 CAR T cell therapy. In this study, we examined the expansion of circulating $T_{N}$, $\mathrm{T}_{\mathrm{CM}}, \mathrm{T}_{\mathrm{EM}}$, and $\mathrm{T}_{\mathrm{E}}$ subsets over time after CAR $\mathrm{T}$ cell infusion. Significantly lower percentages of circulating $\mathrm{CD} 8^{+} \mathrm{T}_{\mathrm{N}}$ cells were detected in patients who ultimately relapsed after CD19 CAR T cell infusion when compared to those who experienced a long-term response. Equally important, $\mathrm{T}_{\mathrm{CM}}, \mathrm{T}_{\mathrm{EM}}$, and $\mathrm{T}_{\mathrm{E}}$ subsets exhibited similar proliferation kinetics when comparing these two patient groups; these indicated that not all circulating $\mathrm{T}$ cell subsets were associated with disease relapse. Our findings suggest that $C D 8^{+} T_{N}$ cells may be the most effective subset to target when generating new adoptive immunotherapy strategies. The percentage of $\mathrm{CD}^{+} \mathrm{T}_{\mathrm{N}}$ cells detected shortly after infusion may serve as a biomarker for long-term prognosis, as this is an independent factor associated with a shorter period of RFS. Interestingly, long-term responders persistently exhibited a more pronounced expansion of $\mathrm{CD}^{+} \mathrm{T}_{\mathrm{N}}$ cells after infusion, although no significant differences with respect to the percentages of $\mathrm{CD}^{+} \mathrm{T}_{\mathrm{N}}$ cells were 
detected at any other time points. A more definitive answer with respect to the role of $\mathrm{CD}^{+} \mathrm{T}_{\mathrm{N}}$ cell percentages at other time points and their role in predicting a long-lasting response will likely require further research, especially as has become increasingly evident, that the endogenous immune system might have direct impact on the CAR T cells administered to patients $[21,45]$.

\section{Conclusions}

The results presented in our study indicate that CD19 CAR $\mathrm{T}$ cells derived from hybridoma clone HI19 $\alpha$ (HI19 $\alpha-4-$ $1 \mathrm{BB}-\zeta$ CAR T) are highly effective against malignant cells in patients diagnosed with R/R B-ALL. Our results also suggest the percentage of circulating $\mathrm{CD}^{+} \mathrm{T}_{\mathrm{N}}$ cells may be developed as a biomarker to predict the long-term prognosis of patients undergoing CAR $\mathrm{T}$ cell therapy.

\section{Supplementary information}

Supplementary information accompanies this paper at https://doi.org/10. 1186/s13045-020-00953-8.

Additional file 1: Supplementary Table 1. Antibodies used for flow cytometry staining of single cell suspensions. Supplementary Table 2. Computational alanine scanning on the complex of CD19 ECD and HI19a sCFv. Supplementary Table 3. Computational alanine scanning on the complex of CD19 ECD and FMC63 scFv. Supplementary Table 4. Nonbond interaction between HI19a and hCD19 ECD. Supplementary Table 5. Non-bond interaction between FMC63 and hCD19 ECD. Supplementary Table 6. Univariate analysis for relapse-free survival. Supplementary Table 7. Multivariate analysis for relapse-free survival.

Additional file 2: Supplementary Fig. 1. Procedure of clinical trial and study flow of all participants. a Scheme for CAR T preparation and treatment. $b$ The diagram shows all study participant's course from the time of consent to treatment on study. Supplementary Fig. 2. Analysis for amplification of different T cell subpopulations after CD19 CAR T cell infusion. a-f, CD8 ${ }^{+} T_{C M}$ cells (a), $C D 4^{+} T_{C M}$ cells (b), $C D 8^{+} T_{E M}$ cells (c), CD4 $^{+} T_{E M}$ cells (d), CD8 ${ }^{+} T_{E}$ cells (e), CD4 ${ }^{+} T_{E}$ cells (f) percentage in peripheral blood after CAR T cell infusion in patients with continuous CR or relapse from B-ALL. Supplementary Fig. 3. The expansion kinetics of Treg cells, NK-like T cells, and NK cells after CD19 CAR T cell infusion. a The correlation between CD19 CAR T cell expansion after infusion and the proliferation of Treg cells. b CD $3^{+} \mathrm{CD} 16^{+} \mathrm{CD} 56^{+} \mathrm{NK}$-like T cells or CD3 $3^{-}$D $16^{+} \mathrm{CD}^{+} 6^{+} \mathrm{NK}$ cells expansion in peripheral blood expansion after CAR T cell infusion. Supplementary Fig. 4. Analysis for amplification of CD19 ${ }^{+} \mathrm{B}$ cells according to relapse. a CD19 $\mathrm{B}$ cells percentage in peripheral blood after CD19 CAR T cell infusion in patients with continuous CR. b CD19+ $\mathrm{B}$ cells percentage in peripheral blood after CD19 CAR T cell infusion in patients who relapsed from B-ALL.

\section{Abbreviations}

CAR T cell: Chimeric antigen receptor-modified T cell; scFv: Single-chain variable fragment; R/R B-ALL: Relapsed/refractory acute lymphoblastic leukemia; hCD19: Human CD19; ECD: Extracellular domain; Ph: Philadelphia chromosome; CNSL: Central nervous system leukemia; Kg: Kilogram; BM: Bone marrow; HSCT: Hematopoietic stem cell transplantation; Tregs: Regulatory $T$ cells; $T_{N}$ : naïve $T$ cells; $T_{C M}$ : Central memory $T$ cells; $T_{E M}$ : Effector memory T cells; $T_{E}$ : Effector T cells; CR/CRi: Complete remission or complete remission with incomplete count recovery; MRD: Minimal residual disease; OS: Overall survival; RFS: Relapse-free survival; AE: Adverse event; Cl: Confidence interval; NCCN: National Comprehensive Cancer Network; MSKCC: Memorial Sloan Kettering Cancer Center; NClCTCAE: National Cancer Institute Common Terminology Criteria for Adverse Events; CRS: Cytokine release syndrome; CRES: CAR T cell-related encephalopathy syndrome

\section{Acknowledgments}

The work was sponsored by Juventas Cell Therapy Ltd. The authors thank the patients and their families, investigators, and coinvestigators.

\section{Authors' contributions}

Jianxiang Wang served as the principal investigator for this study. Ying Wang, Xiaofan Zhu, Dehui Zhou, Fang Liu, and Runxia Gu performed the research, analyzed the data, and wrote the paper. Huijun Wang, Yingxi Xu, Yang Lu, Mengjun Zhong, and Lulu Lv contributed essential reagents or tools. Lugui Qiu, Yingchang Mi, and Min Wang edited the manuscript. Bingcheng Liu, Wei Liu, Xiaojuan Chen, Kaiqi Liu, Ye Guo, Xiaoyuan Gong, Rui Lv, Xia Chen, Chunlin Zhou, and Hui Wei contributed to the patient recruitment and treatment. The author(s) read and approved the final manuscript.

\section{Funding}

This research was supported by grants from the National Natural Science Foundation of China (81830005), National Key Research and Development Program of China (2019YFA0110204), and CAMS Innovation Fund for Medical Sciences (CIFMS 2016-I2M-1-007).

\section{Availability of data and materials}

The datasets used during the current study are available from the corresponding author on reasonable request.

\section{Ethics approval and consent to participate}

This research was approved by the ethical committee in the Institute of Hematology and Blood Diseases Hospital, and all procedures were in accordance with the Helsinki Declaration. Written informed consent was obtained from each participant, in which the informed consent of pediatric patients was provided by their parents or guardians.

\section{Consent for publication}

Not applicable

\section{Competing interests}

Jianxiang Wang received grant from Celgene. The other authors declare that they have no conflict of interest.

\section{Author details}

${ }^{1}$ State Key Laboratory of Experimental Hematology, National Clinical Research Center for Blood Diseases, Institute of Hematology \& Blood Diseases Hospital, Chinese Academy of Medical Sciences \& Peking Union Medical College, Tianjin 300020, China. ${ }^{2}$ Juventas Cell Therapy Ltd., Tianjin 300384, China.

Received: 4 May 2020 Accepted: 17 August 2020

Published online: 07 September 2020

References

1. Grupp SA, Kalos M, Barrett D, Aplenc R, Porter DL, Rheingold SR, et al. Chimeric antigen receptor-modified T cells for acute lymphoid leukemia. N Engl J Med. 2013;368(16):1509-18.

2. Lee DW, Kochenderfer JN, Stetler-Stevenson M, Cui YK, Delbrook C, Feldman SA, et al. T cells expressing CD19 chimeric antigen receptors for acute lymphoblastic leukaemia in children and young adults: a phase 1 doseescalation trial. Lancet. 2015;385(9967):517-28.

3. Maude SL, Frey N, Shaw PA, Aplenc R, Barrett DM, Bunin NJ, et al. Chimeric antigen receptor $\mathrm{T}$ cells for sustained remissions in leukemia. N Engl J Med. 2014;371(16):1507-17.

4. Brudno JN, Somerville RPT, Shi V, Rose JJ, Halverson DC, Fowler DH, et al. Allogeneic T cells that express an anti-CD19 chimeric antigen receptor induce remissions of B-cell malignancies that progress after allogeneic hematopoietic stem-cell transplantation without causing graft-versus-host disease. J Clin Oncol. 2016;34(10):1112-21.

5. Davila ML, Riviere I, Wang X, Bartido S, Park J, Curran K, et al. Efficacy and toxicity management of 19-28z CAR T cell therapy in B cell acute Iymphoblastic leukemia. Sci Transl Med. 2014;6(224):224ra225.

6. Savoldo B, Ramos CA, Liu E, Mims MP, Keating MJ, Carrum G, et al. CD28 costimulation improves expansion and persistence of chimeric antigen receptor-modified T cells in lymphoma patients. J Clin Invest. 2011;121(5): 1822-6. 
7. Sommermeyer D, Hudecek M, Kosasih PL, Gogishvili T, Maloney DG, Turtle $C J$, et al. Chimeric antigen receptor-modified T cells derived from defined CD8+ and CD4+ subsets confer superior antitumor reactivity in vivo. Leukemia. 2016:30(2):492-500.

8. Ying Z, Huang XF, Xiang X, Liu Y, Kang X, Song Y, et al. A safe and potent anti-CD19 CAR T cell therapy. Nat Med. 2019;25(6):947-53.

9. Sotillo E, Barrett DM, Black KL, Bagashev A, Oldridge D, Wu G, et al. Convergence of acquired mutations and alternative splicing of CD19 enables resistance to CART-19 immunotherapy. Cancer Discov. 2015;5(12):1282-95.

10. Fischer J, Paret C, El Malki K, Alt F, Wingerter A, Neu MA, et al. CD19 isoforms enabling resistance to CART-19 immunotherapy are expressed in B-ALL patients at initial diagnosis. J Immunother. 2017;40(5):187-95.

11. An N, Tao Z, Li S, Xing H, Tang K, Tian Z, et al. Construction of a new antiCD19 chimeric antigen receptor and the anti-leukemia function study of the transduced T cells. Oncotarget. 2016;7(9):10638-49.

12. Park JH, Riviere I, Gonen M, Wang X, Senechal B, Curran KJ, et al. Long-term follow-up of CD19 CAR therapy in acute lymphoblastic leukemia. N Engl J Med. 2018;378(5):449-59.

13. Hinrichs CS, Borman ZA, Gattinoni L, Yu ZY, Burns WR, Huang JP, et al. Human effector CD8(+) T cells derived from naive rather than memory subsets possess superior traits for adoptive immunotherapy. Blood. 2011; 117(3):808-14.

14. Xu Y, Zhang M, Ramos CA, Durett A, Liu E, Dakhova O, et al. Closely related T-memory stem cells correlate with in vivo expansion of CAR.CD19-T cells and are preserved by IL-7 and IL-15. Blood. 2014;123(24):3750-9.

15. Kalos M, Levine BL, Porter DL, Katz S, Grupp SA, Bagg A, et al. T cells with chimeric antigen receptors have potent antitumor effects and can establish memory in patients with advanced leukemia. Sci Transl Med. 2011;3(95): 95ra73.

16. Klebanoff CA, Gattinoni L, Restifo NP. Sorting through subsets: which T-cell populations mediate highly effective adoptive immunotherapy? J Immunother. 2012;35(9):651-60.

17. Sabatino M, Hu J, Sommariva M, Gautam S, Fellowes V, Hocker JD, et al. Generation of clinical-grade CD19-specific CAR-modified CD8+ memory stem cells for the treatment of human B-cell malignancies. Blood. 2016; 128(4):519-28.

18. Louis CU, Savoldo B, Dotti G, Pule M, Yvon E, Myers GD, et al. Antitumor activity and long-term fate of chimeric antigen receptor-positive $T$ cells in patients with neuroblastoma. Blood. 2011;118(23):6050-6.

19. Busch DH, Frassle SP, Sommermeyer D, Buchholz VR, Riddell SR. Role of memory T cell subsets for adoptive immunotherapy. Semin Immunol. 2016; 28(1):28-34

20. Wu F, Zhang W, Shao H, Bo H, Shen H, Li J, et al. Human effector T cells derived from central memory cells rather than CD8(+)T cells modified by tumor-specific TCR gene transfer possess superior traits for adoptive immunotherapy. Cancer Lett. 2013;339(2):195-207.

21. Hoffmann JM, Schubert ML, Wang L, Huckelhoven A, Sellner L, Stock S, et al. Differences in expansion potential of naive chimeric antigen receptor $T$ cells from healthy donors and untreated chronic lymphocytic leukemia patients. Front Immunol. 2018;8.

22. Teplyakov A, Obmolova G, Luo J, Gilliland GL. Crystal structure of B-cell coreceptor CD19 in complex with antibody B43 reveals an unexpected fold. Proteins. 2018:86(5):495-500.

23. Li S, Tao Z, Xu Y, Liu J, An N, Wang Y, et al. CD33-specific chimeric antigen receptor $T$ cells with different co-stimulators showed potent anti-leukemia efficacy and different phenotype. Hum Gene Ther. 2018;29(5):626-39.

24. Lee DW, Gardner R, Porter DL, Louis CU, Ahmed N, Jensen M, et al. Current concepts in the diagnosis and management of cytokine release syndrome. Blood. 2014;124(2):188-95.

25. Ghorashian S, Kramer AM, Onuoha S, Wright G, Bartram J, Richardson R, et al. Enhanced CAR T cell expansion and prolonged persistence in pediatric patients with ALL treated with a low-affinity CD19 CAR. Nat Med. 2019:25:1408-14.

26. Gardner RA, Finney O, Annesley C, Brakke H, Summers C, Leger K, et al. Intent-to-treat leukemia remission by CD19 CAR T cells of defined formulation and dose in children and young adults. Blood. 2017;129(25): 3322-31.

27. Locke FL, Ghobadi A, Jacobson CA, Miklos DB, Lekakis LJ, Oluwole OO, et al. Long-term safety and activity of axicabtagene ciloleucel in refractory large B-cell lymphoma (ZUMA-1): a single-arm, multicentre, phase 1-2 trial. Lancet Oncol. 2019;20(1):31-42.
28. Brentjens RJ, Davila ML, Riviere I, Park J, Wang X, Cowell LG, et al. CD19targeted $T$ cells rapidly induce molecular remissions in adults with chemotherapy-refractory acute lymphoblastic leukemia. Sci Transl Med. 2013;5(177):177ra138.

29. Turtle CJ, Hanafi LA, Berger C, Gooley TA, Cherian S, Hudecek M, et al. CD19 CAR-T cells of defined CD4+:CD8+ composition in adult B cell ALL patients. J Clin Invest. 2016;126(6):2123-38.

30. Maude SL, Laetsch TW, Buechner J, Rives S, Boyer M, Bittencourt H, et al. Tisagenlecleucel in Children and Young Adults with B-Cell Lymphoblastic Leukemia. N Engl J Med. 2018;378(5):439-48.

31. Fry TJ, Shah NN, Orentas RJ, Stetler-Stevenson M, Yuan CM, Ramakrishnaet $\mathrm{S}$, et al. CD22-targeted CAR T cells induce remission in B-ALL that is naive or resistant to CD19-targeted CAR immunotherapy. Nat Med. 2018;24(1):20-8.

32. Zhao Y, Liu ZF, Wang X, Wu HT, Zhang JP, Yang JF, et al. Treatment with humanized selective CD19 CAR-T cells shows efficacy in highly treated BALL patients who have relapsed after receiving murine-based CD19 CAR-T therapies. Clin Cancer Res. 2019;25(18):5595-607.

33. Maus MV, Haas AR, Beatty GL, Albelda SM, Levine BL, Liu XJ, et al. T cells expressing chimeric antigen receptors can cause anaphylaxis in humans. Cancer Immunol Res. 2013;1(1):26-31.

34. Neelapu SS. CAR-T efficacy: is conditioning the key? Blood. 2019;133(17): 1799-800.

35. Lowe KL, Mackall CL, Norry E, Amado R, Jakobsen BK, Binder G. Fludarabine and neurotoxicity in engineered T-cell therapy. Gene Ther. 2018;25:176-91.

36. Santomasso BD, Park JH, Salloum D, Riviere I, Flynn J, Mead E, et al. Clinical and biological correlates of neurotoxicity associated with CAR T-cell therapy in patients with B-cell acute lymphoblastic leukemia. Cancer Discov. 2018; 8(8):958-71.

37. Gust J, Hay KA, Hanafi LA, Li D, Myerson D, Gonzalez-Cuyar LF. Endothelial activation and blood-brain barrier disruption in neurotoxicity after adoptive immunotherapy with CD19 CAR-T cells. Cancer Discov. 2017;7(12):1404-19.

38. Yu S, Yi M, Qin S, Wu KM. Next generation chimeric antigen receptor T cells: safety strategies to overcome toxicity. Mol Cancer. 2019;18(1):125.

39. Gattinoni L, Klebanoff CA, Palmer DC, Wrzesinski C, Kerstann K, Yu Z, et al. Acquisition of full effector function in vitro paradoxically impairs the in vivo antitumor efficacy of adoptively transferred CD8+ T cells. J Clin Invest. 2005; 115(6):1616-26.

40. Golubovskaya $\mathrm{V}, \mathrm{Wu}$ L. Different subsets of T cells, memory, effector functions, and CAR-T immunotherapy. Cancers (Basel). 2016;8(3).

41. McLellan AD, Ali Hosseini Rad SM. Chimeric antigen receptor T cell persistence and memory cell formation. Immunol Cell Biol. 2019;97(7):664-74.

42. Gattinoni L, Klebanoff CA, Restifo NP. Paths to stemness: building the ultimate antitumour T cell. Nat Rev Cancer. 2012;12(10):671-84.

43. Hinrichs CS, Borman ZA, Cassard L, Gattinoni L, Spolski R, Yu Z, et al. Adoptively transferred effector cells derived from naive rather than central memory CD8+ T cells mediate superior antitumor immunity. Proc Natl Acad Sci U S A. 2009;106(41):17469-74.

44. Berger C, Jensen MC, Lansdorp PM, Gough M, Elliott C, Riddell SR. Adoptive transfer of effector CD8+ T cells derived from central memory cells establishes persistent T cell memory in primates. J Clin Invest. 2008;118(1): 294-305.

45. Gargett T, Brown MP. Different cytokine and stimulation conditions influence the expansion and immune phenotype of third-generation chimeric antigen receptor T cells specific for tumor antigen GD2. Cytotherapy. 2015;17(4):487-95.

\section{Publisher's Note}

Springer Nature remains neutral with regard to jurisdictional claims in published maps and institutional affiliations. 